\title{
STRONGLY NP-HARDNESS OF SQUARE-FREE SUBSET PRODUCT
}

\author{
THINH D. NGUYEN
}

Definition 1. (Square-free Subset Product problem): We are given $3 N$ integers; find $N$ of them whose product is square free.

Claim 2. We have that $\mathrm{X} 3 \mathrm{C} \leq_{p}$ Square-free Subset Product

In this claim, X3C denotes the well-known Exact Cover by 3 Set problem. Garey and Johnson [1] prove its strong NP-hardness. Now, we prove our claim.

Proof. Starting from a an Exact Cover by 3 sets (X3C) instance (strongly NPC) label each element of the universe with a distinct prime (you can generate $3|X|$ of them in polynomial time); then convert every triple $(x, y, z)$ of the subsets to $x y z$.

It obviously resembles the better known SUBSET PRODUCT (which is not strongly NPC due to the presence of the target product $B$, see [2]).

It can also be modified a little bit to get other variants, like:

- Given $3 N$ integers, find $N$ of them whose product is a perfect 21-th power;

- Given $N$ integers, find a subset whose product is the $3 N$-th primorial.

\section{CONCLUSion}

As long as we study a mathematical conjecture, we should encourage ourselves of having enough labouring hours on Prasolov and Sharygin maths books. Then, reading some articles on theory of computing like [3] is a good practice. Only after that, could we think of the ultimate final for all mathematics sciences.

\section{REFERENCES}

1. Michael R. Garey, David S. Johnson, Computers and Intractability: A Guide to the Theory of NP-Completeness

2. David S. Johnson, The NP-Completeness Column: An Ongoing Guide. pp.393-405

3. Phan Dinh Dieu, Le Cong Thanh, Le Tuan Hoa, Average Polyno-mial Time Complexity of Some NP-Complete Problems, Theor. Comput. Sci. 46(3): pp.219-237 (1986)

Current address: Department of Mathematics, Moscow State University

Email address: kosmofarmer@yandex.com

Key words and phrases. product, square-free, subset.

Perebor. 